\title{
Experimental demonstration of an active latent heat storage concept
}

\author{
Harald Pointner*, Wolf-Dieter Steinmann \\ Institute of Technical Thermodynamics, German Aerospace Center (DLR), Pfaffenwaldring 38-40, \\ 70569 Stuttgart, Germany
}

*Corresponding author. Tel: +49 711 6862-8107. Fax: +49 7116862747

E-mail address: harald.pointner@dlr.de

\section{ABSTRACT}

Latent heat storage allows efficient energy storage in systems with isothermal processes. The low thermal conductivity of cost-effective storage materials is the main challenge in the development of latent heat storage systems. Most of these systems developed so far use extended heat transfer surfaces to ensure sufficient heat transfer rates. The PCMflux concept described in this paper is based on the transport of the storage material across the heat transfer surface. The aim of this approach is to avoid the blockage of the heat transfer surfaces by solidified storage material. The paper gives an overview of the current development of the PCMflux concept including the theoretical analysis and the experimental proof-of-concept.

Keywords: latent heat storage; PCM; active storage; experimental proof-of-concept; PCMflux

\section{Nomenclature}

$\begin{array}{ll}A_{C} & \text { Cross-sectional area of the PCM container }\left(\mathrm{m}^{2}\right) \\ A_{F} & \text { Area of the fluid layer on the heat exchanger }\left(\mathrm{m}^{2}\right) \\ A_{P} & \text { Inner area of heat exchanger pipe }\left(\mathrm{m}^{2}\right) \\ A_{P C M} & \text { Cross-sectional area of the PCM }\left(\mathrm{m}^{2}\right) \\ c_{C} & \text { Specific heat capacity of the container material }(\mathrm{J} / \mathrm{kg} \mathrm{K}) \\ c_{P C M} & \text { Specific heat capacity of the PCM }(\mathrm{J} / \mathrm{kg} \mathrm{K}) \\ d_{P} & \text { Diameter of the heat exchanger pipe }(\mathrm{m}) \\ H_{P C M} & \text { Height of the PCM (m) } \\ K_{F l u x} & \text { Dimensionless number to describe the PCMflux system }(-) \\ L & \text { Heat of fusion of the PCM }(\mathrm{J} / \mathrm{kg})\end{array}$




$\begin{array}{ll}l & \text { Liquid phase } \\ P_{\text {Fin }} & \text { Perimeter of the Heat exchanger fin }(\mathrm{m}) \\ \dot{Q} & \text { Heat flow }(\mathrm{W}) \\ \dot{q} & \text { Inner heat exchanger pipe surface related heat flux }\left(\mathrm{W} / \mathrm{m}^{2}\right) \\ \dot{q}_{\max } & \text { Nominal heat flux of a specific module configuration }\left(\mathrm{W} / \mathrm{m}^{2}\right) \\ S_{\text {Fin }} & \text { Length of the heat exchanger fin }(\mathrm{m}) \\ s & \text { Solid phase } \\ T_{m(, F)} & \text { Melting temperature of the PCM (Fluid) }\left({ }^{\circ} \mathrm{C}\right) \\ v & \text { Forward velocity of the PCM }(\mathrm{m} / \mathrm{s}) \\ v_{\max } & \text { Nominal PCM forward velocity of a specific module configuration }(\mathrm{m} / \mathrm{s}) \\ W_{C} & \text { Width of the container wall }(\mathrm{m}) \\ W_{F} & \text { Width of the fluid layer }(\mathrm{m})\end{array}$

\section{Greek symbols}

$\begin{array}{ll}\rho_{C} & \begin{array}{l}\text { Density of the container Material }\left(\mathrm{kg} / \mathrm{m}^{3}\right) \\ \rho_{P C M}\end{array} \\ \Delta \mathrm{T} & \begin{array}{l}\text { Density of the storage material }\left(\mathrm{kg} / \mathrm{m}^{3}\right) \\ \text { Temperature difference }(\mathrm{K})\end{array} \\ \text { Abbreviations } & \\ \text { HTF } & \text { Heat transfer fluid } \\ \text { HTS } & \text { Heat transfer structure } \\ \text { PCM } & \text { Phase change material } \\ \text { SHE } & \text { Screw heat exchanger } \\ \text { QP } & \text { Quasi-stationary phase change interface } \\ \text { ZnSe } & \text { Zinc selenide }\end{array}$

\section{Introduction}

The main advantage of latent heat storage systems is the ability to store heat in a narrow temperature range. This allows the effective storage in applications that include isothermal processes, such as steam processes in industry or in power plants [1]. The option to integrate storage capacity is a key feature of solar thermal power plants. If steam is used as heat transfer medium in the solar absorbers, latent heat 
storage systems enable a high second law efficiency. In the temperature range from $150{ }^{\circ} \mathrm{C}$ to $350{ }^{\circ} \mathrm{C}$, nitrate salts are often used as phase change material (PCM) [1]-[5]. While these materials are cost attractive, they have a low thermal heat conductivity [6]-[8] which causes performance problems while operating the storage system. While discharging, the PCM first crystallizes in regions close to the heat exchanger and sticks on it. With the ongoing discharging process, this layer of frozen PCM around the heat exchanger grows, as shown in Fig. 1. Within this solid layer, no convection effects can improve heat transfer and heat conduction represents the dominating heat transportation mechanism. Here, the poor thermal heat conductivity becomes important. With a growing solid PCM layer around the heat exchanger, the thermal resistance between the liquid PCM and the heat transfer fluid (HTF) inside the heat exchanger increases steadily. This results in a declining heat flux during the discharge process [3], [9].

Various concepts have been suggested to overcome the limitation resulting from the low thermal heat conductivity of the PCM by enlarging the heat transfer area by the deployment of fins [5], [10]-[16]. Among others, some concepts address the challenge with increasing the effective thermal heat conductivity of the PCM either by integrating the PCM into highly conductive matrices [3], [17]-[22] or improving heat transfer by the deployment of heat pipes [23]-[26]. Most of these concepts can be considered as passive PCM storage systems using heat exchangers embedded into the storage material. With the enlargement of the capacity of such storage systems, the heat transfer structure (HTS) inside the PCM must also be enlarged in order to secure a sufficient heat transfer. Therefore, no considerable cost savings can be expected for large scale latent heat storage systems of such a type.

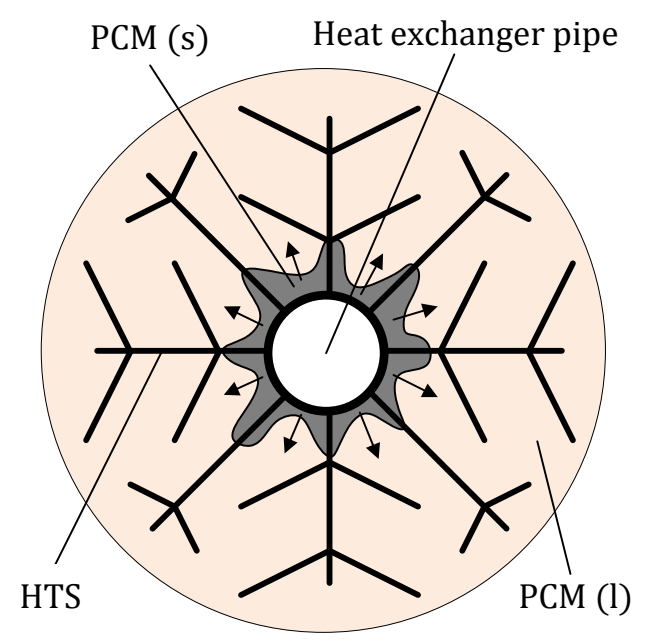

Fig. 1: Cross-section of an example of a latent heat storage module with heat exchanger pipe, attached heat transfer structure (HTS) and the growing layer of solidified PCM during discharging 
In active PCM storage systems the storage material is separated mechanically from the heat transfer section. During charging and discharging the storage material is transported across thus section and is thereby independent of the capacity of the storage system. Essential for active PCM storage systems is the close thermal contact in the heat transfer area. This area must not be covered by solidified PCM.

One active latent heat storage system is the Screw Heat Exchanger (SHE) concept developed by Zipf et al. [27]. Here, the PCM is transported steadily by a rotating double screw system from one end to the other. While passing the screw heat exchangers, the PCM changes phase. The screw flights of the heat exchangers scratch off the crystallized PCM from each other and the establishment of a growing layer of solid PCM is avoided.

The novel active latent heat storage concept described and experimentally demonstrated in this article is called PCMflux. It aims for a constant and controllable discharging heat flux at a high level with a potentially low deployment of auxiliary materials. It represents a new active latent heat storage concept and its application is thereby not limited to solar thermal power plants. Without significant changes in its design, it also comes into consideration for raising the energy efficiency of e.g. industrial processes in a wide range of temperatures with a linked HTF system that undergoes a change of aggregate state.

\section{The PCMflux concept}

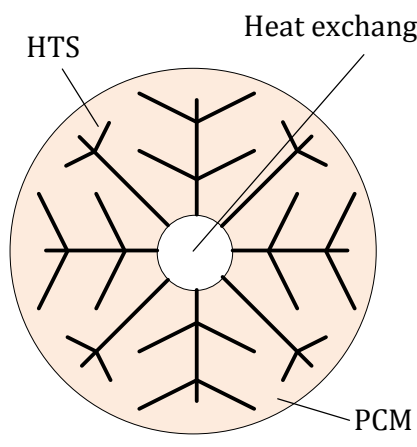

(a)

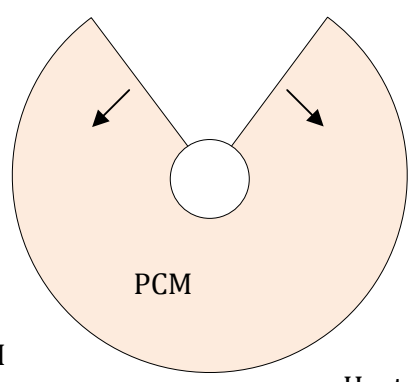

(b)

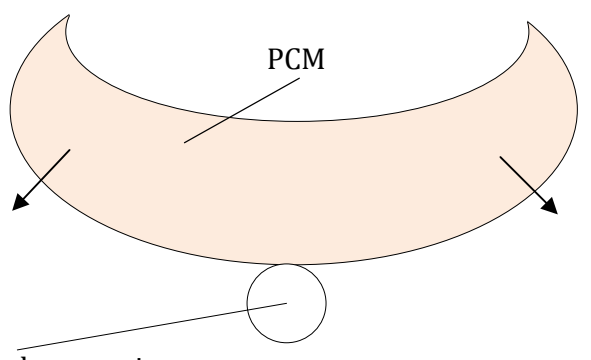

(c)

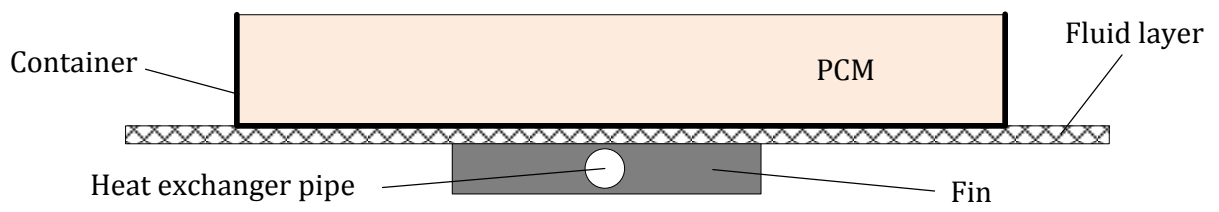

(d)

Fig. 2: Development of the PCMflux concept starting from the state-of-the-art with heat transfer structure (HTS) (a) over the unrolling of the PCM from the heat exchanger $(b+c)$ to a general PCMflux module $(d)$ 
To overcome the heat flux drop while discharging within the PCMflux concept, the storage material (capacity) is mechanically separated from the heat exchanger (power) [9], [28]. Starting from the stateof-the-art in latent heat storage, the stages in the development of the PCMflux concept are schematically visualized in Fig. 2. Fig. 2 (a) shows a cross-sectional cut of a heat exchanger pipe with attached HTS to increase the discharging heat flux representing the state-of-the-art, see also Fig. 1.

Here, the HTS covers the whole cross-sectional area in order to enable a sufficient heat flux at the end of a discharging cycle as well. Within the basic concept of the PCMflux system, no HTS is necessary. Implementing the separation of power and capacity, the PCM is unrolled off the heat exchanger pipe. This development process is visualized within Fig. 2 (b)+(c). After this separation of the PCM from the heat exchanger, the PCM is filled into a container that is located above the heat exchanger. This configuration is the basis of the PCMflux concept, see Fig. 2 (d). As a consequence, the storage material now can be moved both in liquid and solid state towards the locally-fixed heat exchanger.

To charge the storage system, the container is moved in one direction and to discharge in the other one. To ensure good thermal contact between the PCM container and the heat exchanger, a fluid layer is introduced between these components to avoid dry contact. A nitrate salt mixture with a low melting temperature is chosen as a fluid layer. The influence of this fluid layer on the thermal contact was experimentally investigated in a separate study [29]. Compared to dry contact, an improvement of a factor of 9.9 can be realized [29].

The heat exchanger consists of a heat exchanger pipe with attached fins, see Fig. 2 and Fig. 3. These fins are thereby not integrated into the PCM and remain independent of the capacity of the storage system. Hence, this heat exchanger needs to be designed according to the necessary thermal power of the system only. This promises cost advantages for large scale systems compared to the state-of-the-art.

All heat transfer between the HTF inside the heat exchanger pipe and the storage material occurs on top of the heat exchanger, see the 'area of heat transfer' in Fig. 3. No heat is transferred between the PCM and the HTF before entering the heat exchanger or after leaving it. 


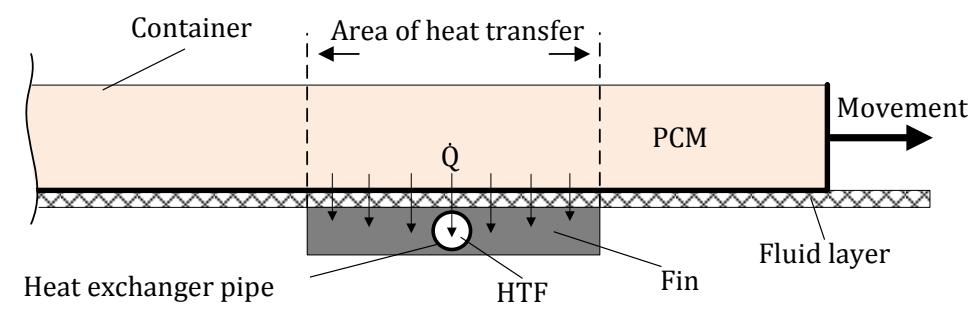

Fig. 3: Scheme of the PCMflux concept with its main components in the case of discharging

If the forward velocity of the storage material is chosen within a certain range, a quasi-stationary state inside the PCM can be established. In this case, the amount of freezing PCM corresponds to the amount of PCM that is transported into the system and a locally-fixed phase change interface is established even though the container is in motion.

After reaching this state, a constant heat flux is realized over the whole discharging period. This constant heat flux can be controlled by adjusting the forward velocity.

\section{Theoretical Analysis}

The following section outlines the theoretical analysis of the PCMflux concept. In a first step, numerical results showing the constant and controllable heat flux during the discharge of the storage unit are given. These are then used to examine the correlation between forward velocity and resulting heat flux.

\subsection{Constant and controllable heat flux}

A developed 2D transient simulation model is used to investigate the correlation between forward velocity $v$ of the PCM container and the resulting heat flux $\dot{q}$ related to the inner heat exchanger pipe surface. Details about this tool can be found in [4].

Fig. 4 shows an example of a PCMflux module configuration with its corresponding parameters. At the beginning of the numerical investigation, a reference PCMflux module configuration is defined. This reference configuration is not an optimized version of a PCMflux module, but it offers the possibility to examine the influence of each parameter. The corresponding data of the reference system regarding material properties, geometry and process parameters are given in Tab. 1. 


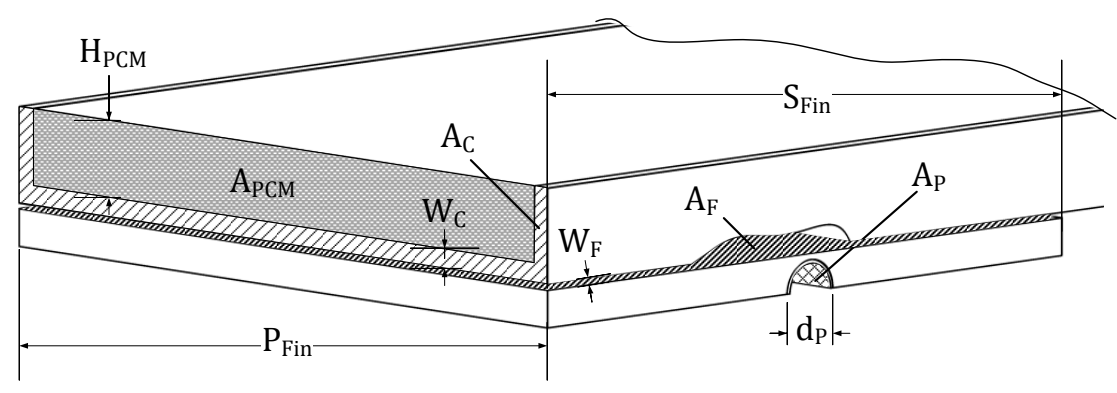

Fig. 4: Sketch of a general PCMflux module with its main parameters

Tab. 1: Material, geometry and process data of the PCMflux reference module configuration with steel PCM containers

\begin{tabular}{ccc|ccc}
\hline Parameter & Value & Unit & Parameter & Value & Unit \\
\hline $\boldsymbol{H}_{\boldsymbol{P C M}}$ & 20.00 & $\mathrm{~mm}$ & $\boldsymbol{c}_{\boldsymbol{P C M}}(\boldsymbol{l} / \boldsymbol{s})$ & 1421.00 & $\mathrm{~J} / \mathrm{kgK}$ \\
\hline $\boldsymbol{A}_{\boldsymbol{P C M}}$ & 200.00 & $\mathrm{~cm}^{2}$ & $\boldsymbol{c}_{\boldsymbol{C}}($ Steel $)$ & 481.00 & $\mathrm{~J} / \mathrm{kgK}$ \\
\hline $\boldsymbol{A}_{\boldsymbol{C}}$ & 10.40 & $\mathrm{~cm}^{2}$ & $\boldsymbol{\rho}_{\boldsymbol{P C M}}(\boldsymbol{l} / \boldsymbol{s})$ & 2017.50 & $\mathrm{~kg} / \mathrm{m}^{3}$ \\
\hline $\boldsymbol{A}_{\boldsymbol{P}}$ & 320.00 & $\mathrm{~cm}^{2}$ & $\boldsymbol{\rho}_{\boldsymbol{C}}($ Steel $)$ & 7872.00 & $\mathrm{~kg} / \mathrm{m}^{3}$ \\
\hline $\boldsymbol{W}_{\boldsymbol{F}}$ & 1.00 & $\mathrm{~mm}$ & $\boldsymbol{L}$ & 108.00 & $\mathrm{~kJ} / \mathrm{kg}$ \\
\hline $\boldsymbol{\Delta} \boldsymbol{T}$ & 10.00 & $K$ & & & \\
\hline
\end{tabular}

The constant heat flux over time of the reference configuration with a forward velocity of $v_{1}=$ $0,014 \mathrm{~mm} / \mathrm{s}$ is visualized in Fig. 5 . Additionally, the simulation results for discharging the reference configuration stationarily are given in Fig. 5. 


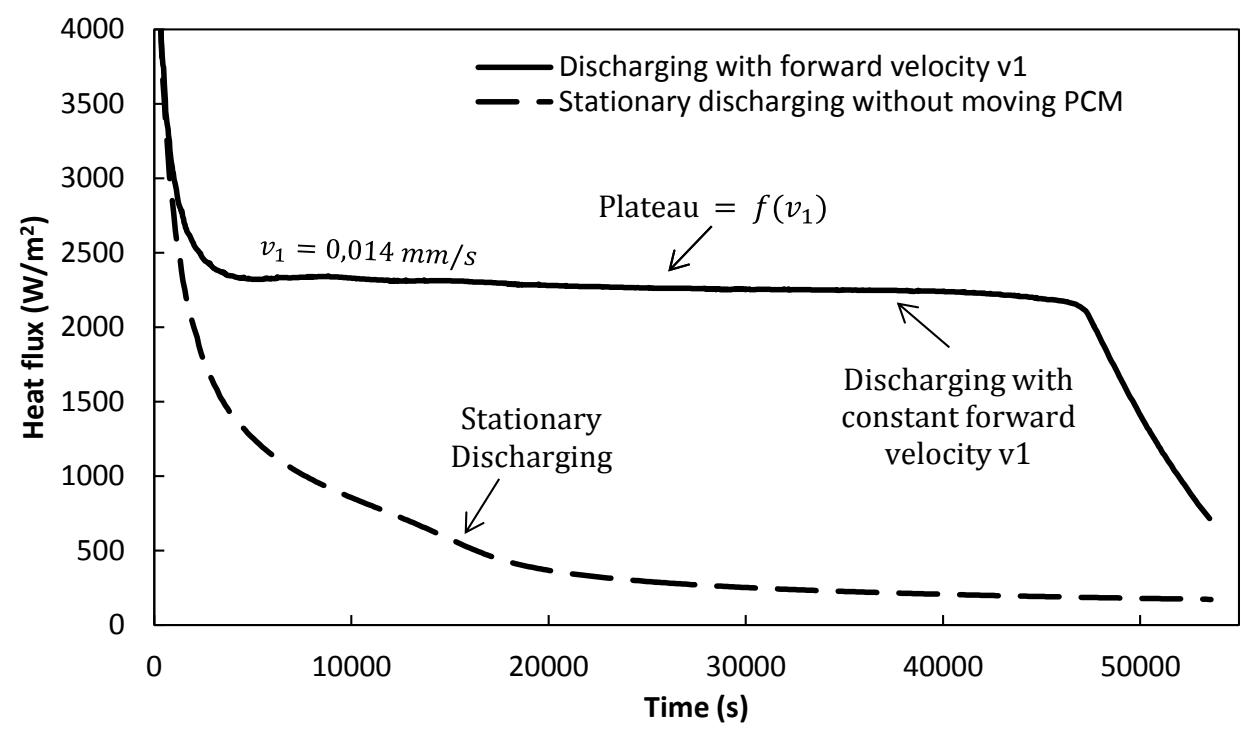

Fig. 5: Comparison of the resulting heat flux while discharging the PCMflux reference module configuration with moving and stationary storage material

The characteristic heat flux drop for passive latent heat storage systems can be observed when the PCM is motionless (stationary). In contrast, moving the PCM with the velocity $v_{1}$ leads to a nearly constant plateau with its corresponding quasi-stationary state as shown in Fig. 5. At the beginning of the discharging process, a significant drop of heat flux even for the active system can be seen. This is due to the comparably fast sensible cooling of the materials from the previous charging process. This cooling process results in high heat fluxes at the beginning of the discharging process. As soon as the materials have the discharging temperature, the resulting heat flux is only due to the release of energy by the crystallizing PCM. In this phase of the discharging process, the heat flux stabilizes and a nearly-constant plateau is established.

At the end of the discharging process, the PCM container no longer covers the whole heat exchanger which results in a further drop of the heat flux. This state, however, can be prolonged arbitrarily according to specific needs by enlarging the PCM container with the integrated PCM or increasing the storage system's capacity, respectively.

By varying the forward velocity, the resulting heat flux can be controlled, see Fig. 6. Here, the forward velocity is reduced from $v_{1}=0,014 \mathrm{~mm} / \mathrm{s}$ to $v_{2}=0,0063 \mathrm{~mm} / \mathrm{s}$ while discharging. This results in the establishment of a new quasi-stationary state with a new nearly-constant plateau at a lower level. At the end of the discharging process, a similar final drop of the heat flux occurs as described previously. 
Fig. 5 and Fig. 6 show two important findings: First, nearly-constant plateaus of the heat flux while discharging are possible by moving the PCM. And secondly, these constant plateaus can be controlled by varying the forward velocity $v$. The correlation between heat flux and forward velocity is examined in the following section.

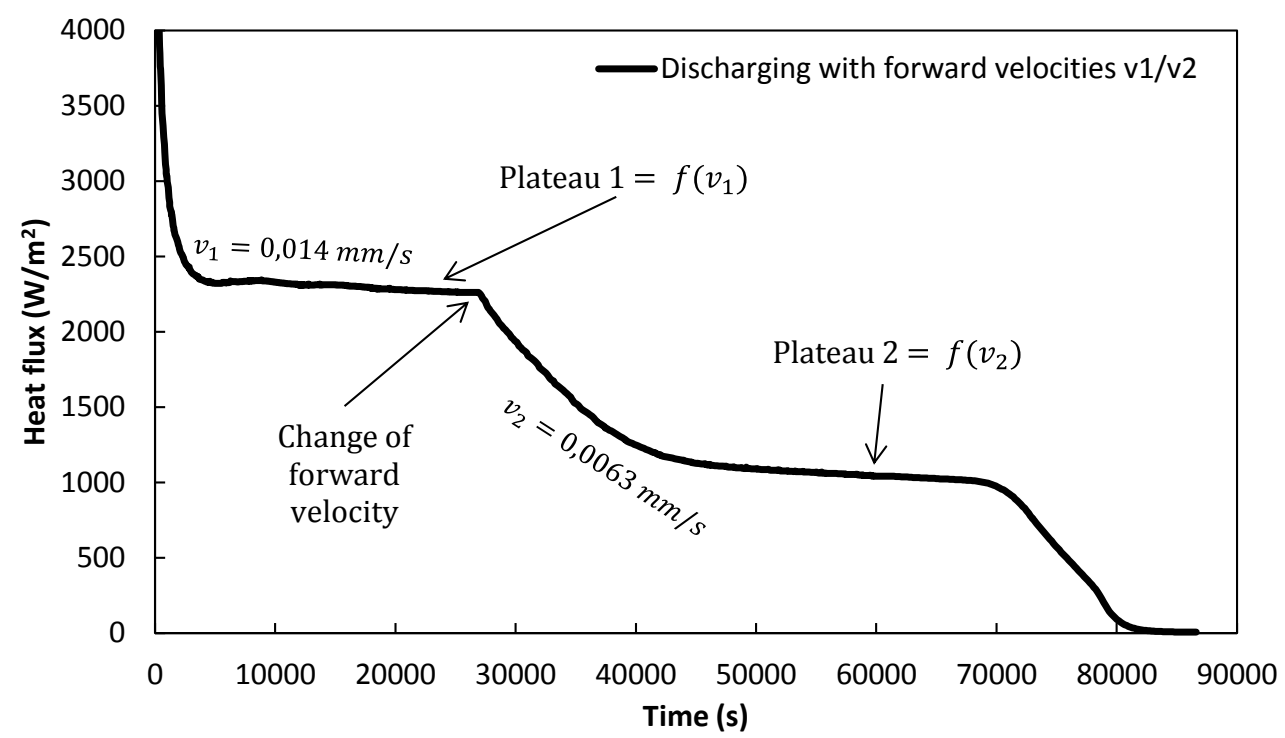

Fig. 6: Resulting heat flux of the reference PCMflux configuration with changing the forward velocity from v1 to v2 with the establishment of a different constant plateau

\subsection{Correlation of forward velocity and heat flux}

Two parameters were found by the simulation results to be crucial for describing the correlation of $v$ and $\dot{q}$. These two parameters are material properties of the PCM, namely its density $\rho_{P C M}$ and its heat of fusion $L$ [9]. Using the Buckingham`s Pi Theorem [30], a dimensionless number $K_{F l u x}$ is developed to describe the relation between $v$ and $\dot{q}$. It can be found as [31]:

$$
K_{\text {Flux }}=\frac{\rho_{P C M} \cdot L \cdot v}{\dot{q}}
$$

$K_{\text {Flux }}$ describes the ratio between the heat flux that enters the system from the heat of fusion of the PCM (numerator) and the total heat flux entering or leaving the system through the heat exchanger pipe (denominator). If an absolute value for $K_{F l u x}$ is known, the forward velocity $v$ specific resulting heat flux $\dot{q}$ can be determined immediately by rearranging equation (1):

$$
\dot{q}=\frac{\rho_{P C M} \cdot L}{K_{F l u x}} \cdot v
$$


Unfortunately, a corresponding pair of $v$ and $\dot{q}$ has to be known, e.g. from simulation, in order to calculate the module specific value of $K_{F l u x}$. Expanding equation (1) by the cross-sectional area of the PCM $A_{P C M}$ and the inner heat exchanger pipe surface $A_{P}$, see Fig. 4 , an explicit formula to calculate an absolute value for $K_{F l u x}$ without knowing the forward velocity $v$ can be given following [9], [31]:

$$
K_{\text {Flux }}=\frac{A_{P} \cdot \rho_{P C M} \cdot L}{A_{P C M} \cdot \rho_{P C M}\left(L+c_{P C M} \cdot \Delta T\right)+A_{C} \cdot \rho_{C} \cdot c_{C} \cdot \Delta T}
$$

Additional to the previously mentioned parameters, equation (3) contains the specific heat capacities of the storage and container material $C_{P C M}, c_{C}$ and the temperature difference $\Delta T$ between the temperature of the HTF and the melting temperature of the PCM. With equation (3), $K_{F l u x}$ can be calculated directly with only knowing the general geometry details, material properties and the design temperature difference. No simulations have to be done to find the module specific value for $K_{\text {Flux }}$.

The correlation between $v$ and $\dot{q}$ can be visualized by defining a characteristic curve. Within this characteristic curve, the level of constant heat flux as a function of the forward velocity of a specific module configuration is given. As an example, see Fig. 7. Here, the simulation results consisting of the averaged quasi-stationary levels of heat flux and the corresponding forward velocities for the reference PCMflux module configuration are shown.

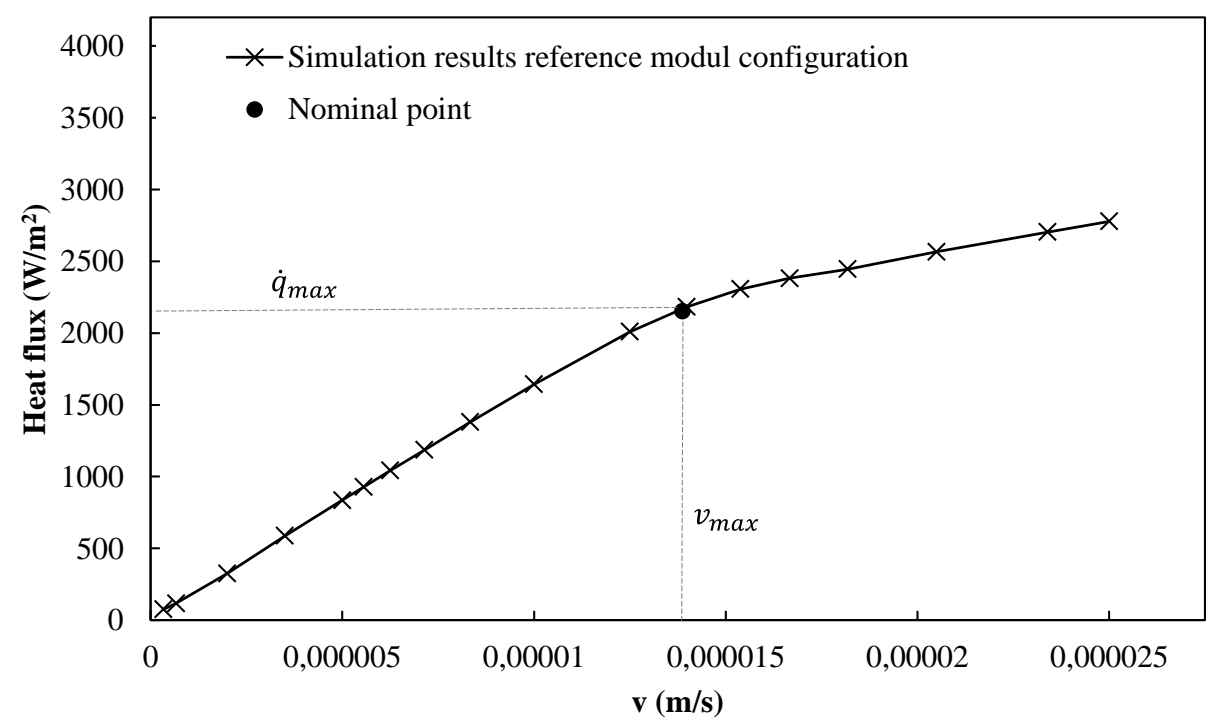

Fig. 7: Characteristic curve for the reference PCMflux module configuration established from simulation results showing the values of the quasi-stationary and nearly constant heat fluxes as a function of the forward velocity 
For small values of $v$, the correlation between the heat flux and the forward velocity is nearly linear. From one point on, the curve leaves its linear shape and flattens. This point corresponds to the nominal parameters $\left(v_{\text {max }}, \dot{q}_{\text {max }}\right)$ of the regarded module configuration and is therefore called the "Nominal point". Adding to this curve the results via equation (2) and $K_{F l u x}=1.40$, see equation (3) and Tab. 1, leads to Fig. 8. Here, the linear correlation of the heat flux and the forward velocity in the "linear operational area" can be seen. The line produced with $K_{F l u x}$ and equation (2) fits well to the numerical results in this area.

After increasing the forward velocity over the nominal point, see Fig. 8 , the analytical line and the simulation results curve deviate significantly. As soon as this behavior is observed, the forward velocity chosen is too fast and the PCM inside the container does not have enough time to change phase completely. Since $K_{\text {Flux }}$ is developed for complete phase change only, it is only valid for the linear operational area.

Within the operation of the PCMflux concept, all states indicated in Fig. 8 by "Possible operational points" can be adjusted by varying the forward velocity of the storage material. Therefore, the desired heat fluxes can be controlled. Each point along the linear operational area leads to a quasi-stationary state with complete phase change and constant thermal power over time. The two states with the forward velocities $v_{1}$ and $v_{2}$ shown in Fig. 6 are also indicated in Fig. 8.

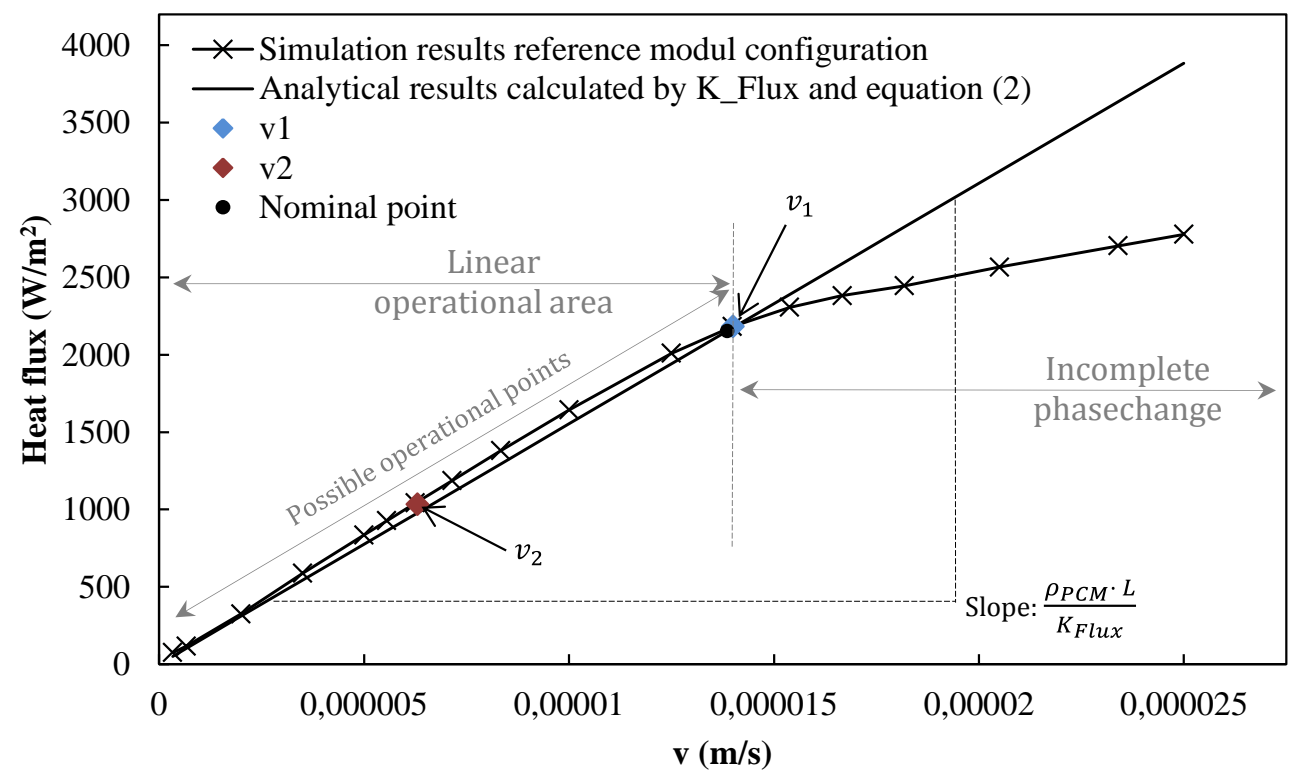

Fig. 8: Characteristic curve for the reference PCMflux module configuration established from simulation results together with the analytical K_Flux-based line valid for the linear operational area 
The position of the quasi-stationary phase change interface on the heat exchanger corresponds to the forward velocity and to the resulting heat flux. The slower the PCM is moved, the closer this position is located at the entrance of the heat exchanger. If it is moved faster, this quasi-stationary phase change interface can be found closer to the end of the heat exchanger, see Fig. 9. If it is moved at the module specific nominal velocity $v_{\max }$, the quasi-stationary phase change interface is located exactly at the end of the fin, see Fig. 9 (a).

In order to control the heat flux of the storage system, the forward velocity can be reduced from this state $\left(v<v_{\max }\right)$. This results in the establishment of a quasi-stationary phase change interface before the end of the fin, see Fig. 9 (b). Here, not the whole area of the heat exchanger is used for heat transfer. This results in a lower but still constant level of the heat flux. If the storage material is moved too fast $\left(v>v_{\max }\right)$, an incomplete phase change occurs, see Fig. 9 (c). In order to secure the utilization of the whole storage material, this situation must be avoided.

In [9] an iterative method to calculate the nominal point is described. This method allows the prediction of the nominal point regarding additional influence factors. These factors are the shape of the heat exchanger, the width of the fluid layer, the height of the PCM layer inside the container and all materials both latent and sensible such as steel, aluminum, the fluid and the PCM. With the instruments given so far, the PCMflux concept can be designed and operated.

(a) phase change interface at the end of the fin

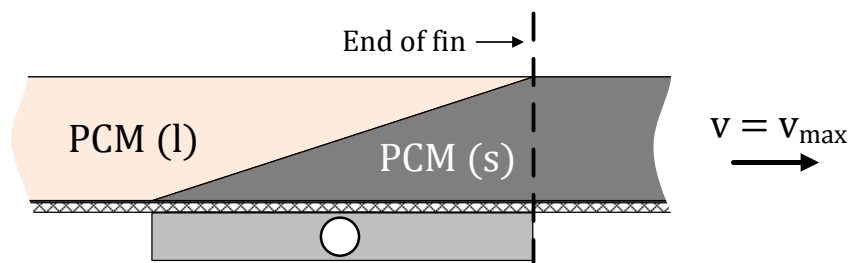

(b)

Quasistationary phase change interface before the end of the fin

$$
\text { Incomplete phase }
$$
change

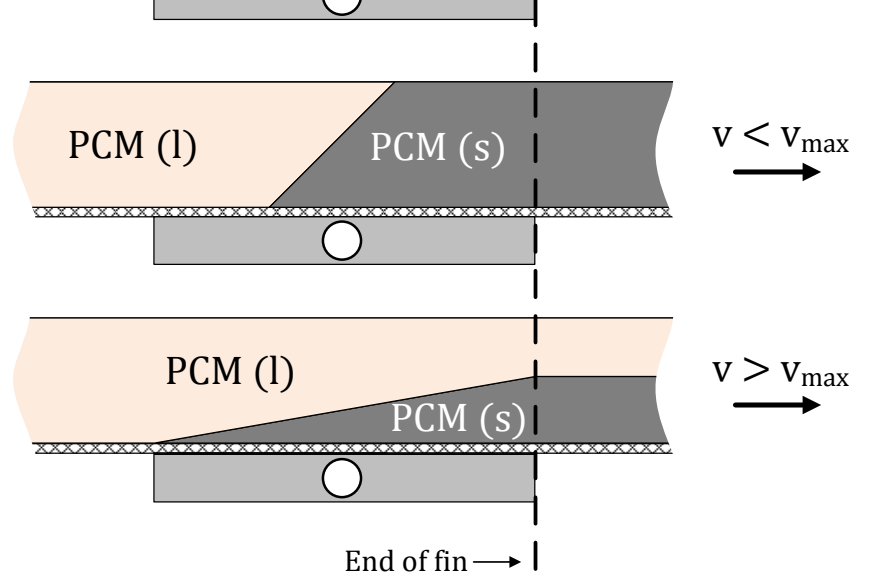

Fig. 9: Position of the quasi-stationary phase change interface at (a) the end of the fin with the maximum forward velocity $v=v_{\max }$, (b) before the end of the fin with $v<v_{\max }$ and (c) incomplete phase change with $v>v_{\max }$ 


\section{Experimental Analysis}

Within this section, the experimental setup to proof the PCMflux concept is described. Moreover, the methodology to validate the theory outlined in the last section is given. The last part of this section shows the corresponding experimental results and the experimental feasibility of the PCMflux concept.

\subsection{Experimental setup}

The experimental setup's schematic overview is shown in Fig. 10. Compared to the described basic concept, the PCM is not filled into one single container. The PCM is separated into several small containers. The containers are connected by wires. The wires are used to pull the containers by a transport mechanism into the requested direction in order to move the PCM.

Using smaller containers rather than one big container has an advantage: The smaller containers are not as stiff as one large container. Hence, the containers can sink into the heat exchanger while entering the heat transfer area and rise in order to leave it, see Fig. 10. This allows the heat exchanger to be bowlshaped. With such a heat exchanger, the contacting fluid layer does not have to cover the whole setup, but only the area of the heat exchanger. This way less fluid is needed to improve heat transfer between PCM containers and heat exchanger.

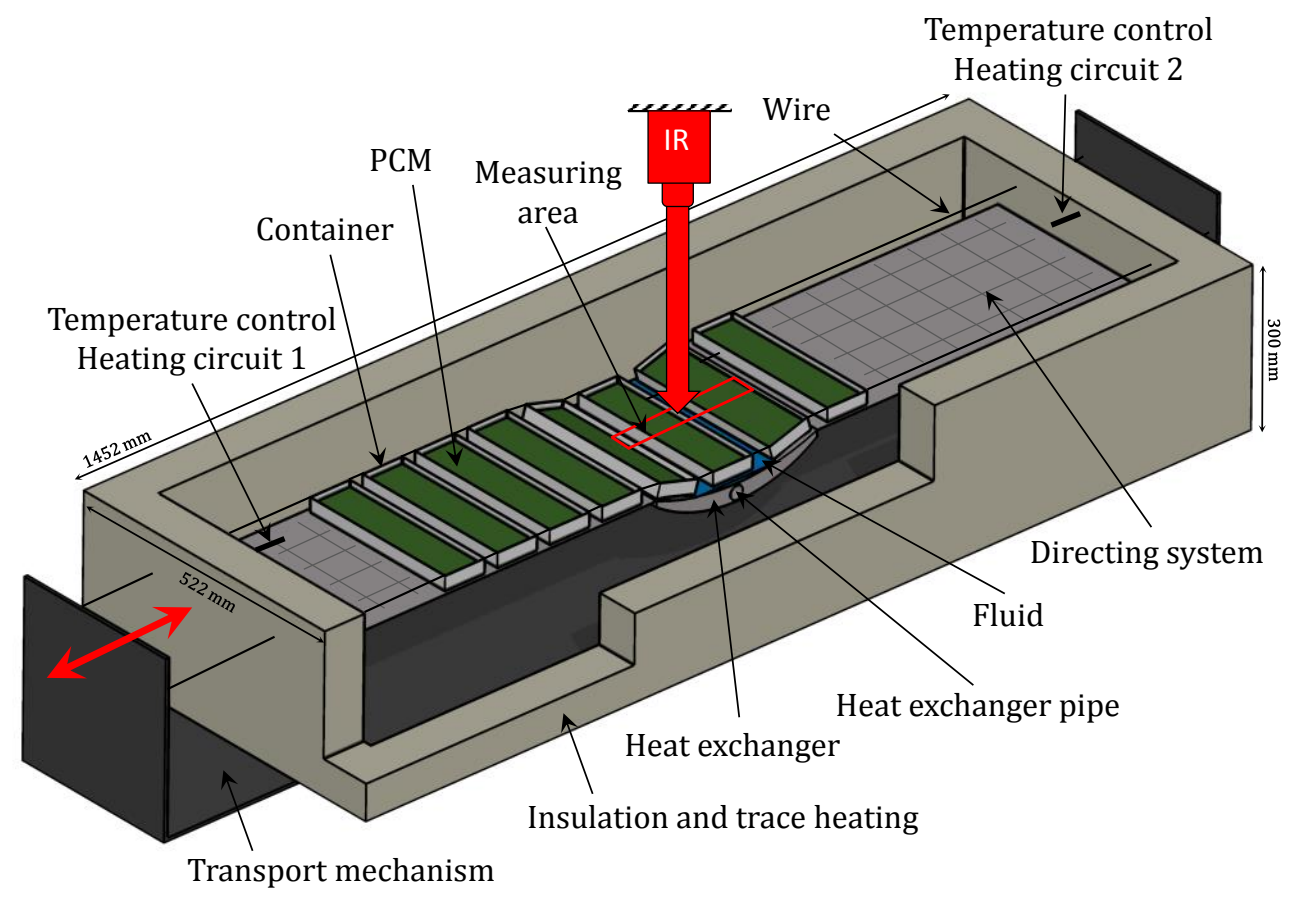


Fig. 10: Schematic overview of the experimental proof-of-concept of the PCMflux concept with all main components

An image and a sketch of the heat exchanger flanged to the heat exchanger pipe can be seen in Fig. 11 (a) + (b). The bowl-shape is approximated by a ramp system. The PCM containers entering the system slide down into the heat exchanger and are moved up at the other end. As soon as the PCM containers leave the ramp system downwards, they are in full contact with the heat exchanger. As they reach the ramp system on the other end of the heat exchanger, this full contact ends with starting to lift the containers. That is why the distance in between the ramp systems of the heat exchanger is called the "active length" of the heat exchanger, see Fig. 11 (b). For further examinations it is assumed that all heat is transferred within this active length and the area of the ramps is inactive for heat transfer.

A thermal oil supplier unit is connected to the heat exchanger pipe. With this thermal oil as HTF, the temperature of the heat exchanger is controlled, see Fig. 12. While the PCM containers are on the heat exchanger, the PCM changes phase. No heat is transferred while they are on the directing system, see Fig. 10 and Fig. 12 (b). The directing system carries the weight of the PCM containers and leads them to and from the heat exchanger. Since the PCM containers only have to withstand small forces, the containers are made of aluminum foil with a wall thickness of $0.2 \mathrm{~mm}$. This reduces the necessary amount of wall material and ensures good thermal contact.

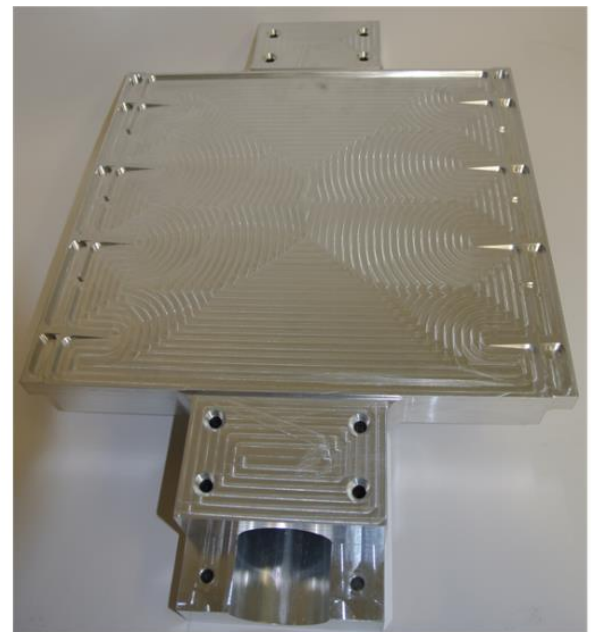

(a)

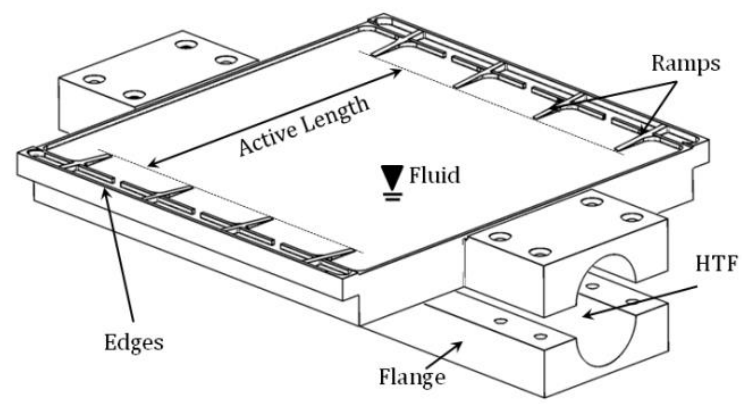

(b)

Fig. 11: Heat exchanger with flange, ramps to support the PCM containers entering and leaving the heat exchanger and the active length of the heat exchanger with full surface contact between the PCM containers and heat exchanger

The experimental setup is insulated in order to minimize heat losses. Additionally, two heating circuits are integrated into the insulation. These are controlled by two thermocouples at the outer ends of the 
setup, see Fig. 10. This enables the accurate control of the inner temperature of the experimental setup, which is set at the PCM's melting temperature.

The position of the phase change interface of the PCM inside the containers is observed via thermography. Thereby, the infrared camera is mounted over the experimental setup, see. Fig. 10 and Fig. 12. In order to enable the infrared rays to pass the cover insulation, a ZnSe crystal is integrated into it, see Fig. 12 (a). This window withstands temperatures in the considered range and is permeable for both optical and infrared rays. The resulting measurement area is shown in Fig. 10 and Fig. 12. It consists of the inner part of the PCM containers to reduce the influence of boundary effects and covers the whole length of the heat exchanger. As a consequence, the whole phase change process of the PCM inside the containers can be observed simultaneously.

The movement is realized by a positioning motor connected to the transport mechanism via a drive system including a reducing gear with the factor of 627.73 . This allows for small forward velocities in the range of $v=1,8-33,0 \mathrm{~mm} / \mathrm{min}$ with acceptable relative errors of $0,25-2,00 \%$.

As storage material, the eutectic nitrate salt mixture $\mathrm{KNO}_{3}(54 w t \%)-\mathrm{NaNO}_{3}(46 w t \%)$ with a melting temperature of $T_{m}=222^{\circ} \mathrm{C}$ is used. The fluid layer consists of a nitrate salt mixture with a lower melting temperature $T_{m, F}=140-142{ }^{\circ} \mathrm{C}$ [32], [33] that is commercially available named Hitec. It has a composition of $\mathrm{NaNO}_{3}(7 w t \%)-\mathrm{KNO}_{3}(53 w t \%)-\mathrm{NaNO}_{2}(40 w t \%)$. The difference of the specific melting temperatures between the PCM and the fluid secures a liquid fluid layer throughout the experiments. Even while discharging the PCM, the fluid layer stays liquid. This excludes the interference of the PCM containers' movement by the fluid layer. 


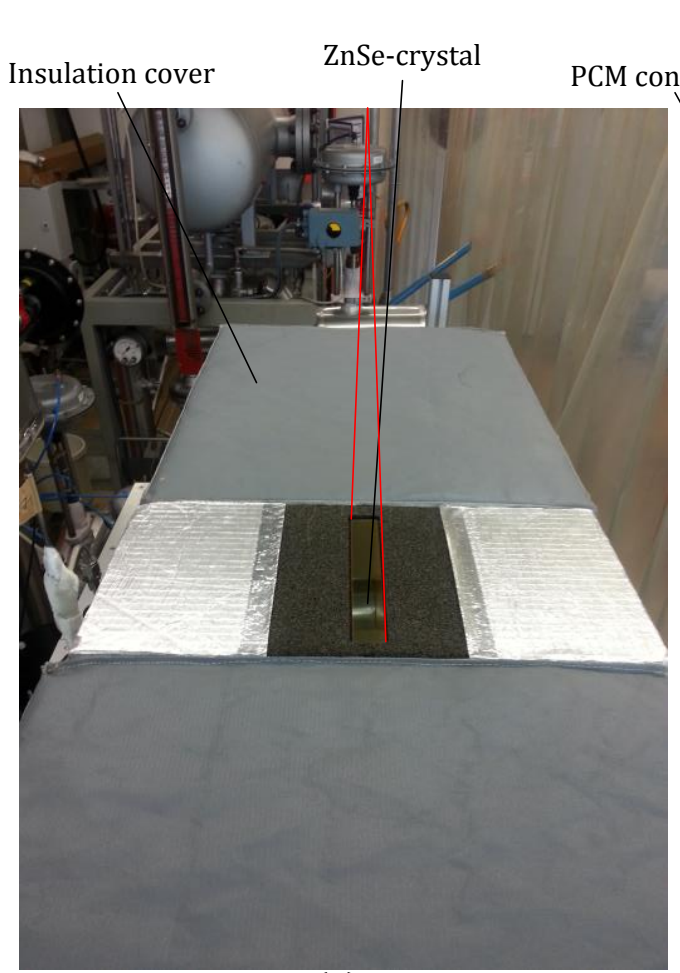

(a)

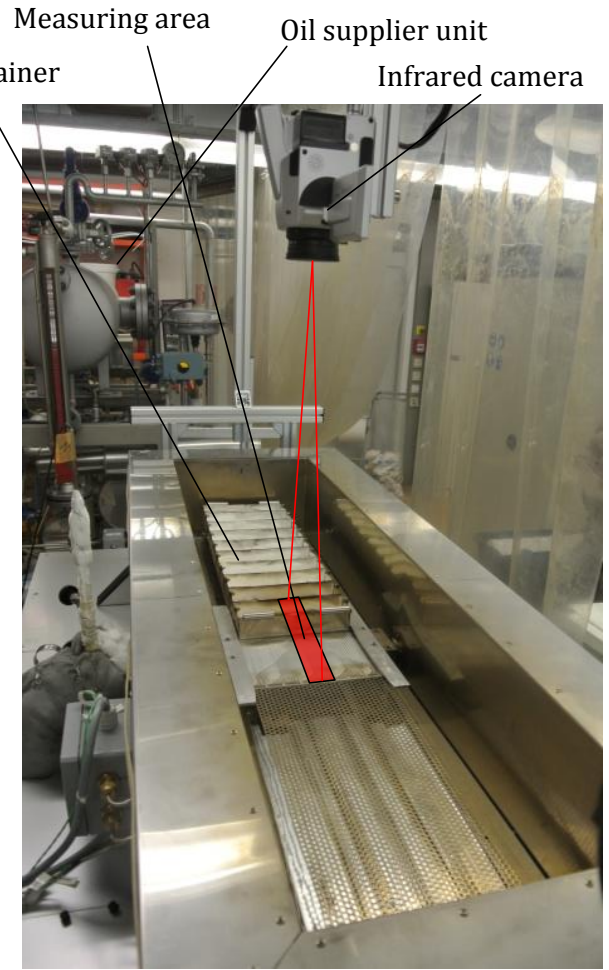

(b)

Fig. 12: Images of the experimental setup with the ZnSe-window in the top cover insulation (a) and the PCM containers, the directing system and the infrared camera without top cover (b).

The corresponding material, geometry and process data of the experimental proof-of-concept can be found in Tab. 2.

Tab. 2: Material, geometry and process data of the experimental proof-of-concept with aluminum PCM containers with measured heat of fusion, for $K_{\text {Flux }}$ see equation (3)

\begin{tabular}{ccc|ccc}
\hline Parameter & Value & Unit & Parameter & Value & Unit \\
\hline $\boldsymbol{H}_{\boldsymbol{P C M}}$ & $5.00 ; 10.00$ & $\mathrm{~mm}$ & $\boldsymbol{c}_{\boldsymbol{P C M}}(\boldsymbol{l} / \boldsymbol{s})$ & 1421.00 & $\mathrm{~J} / \mathrm{kgK}$ \\
\hline $\boldsymbol{A}_{\boldsymbol{P C M}}$ & $9.50 ; 19.00$ & $\mathrm{~cm}^{2}$ & $\boldsymbol{c}_{\boldsymbol{C}}$ (Aluminum) & 1080.00 & $\mathrm{~J} / \mathrm{kgK}$ \\
\hline $\boldsymbol{A}_{\boldsymbol{C}}$ & 0.58 & $\mathrm{~cm}^{2}$ & $\boldsymbol{\rho}_{\boldsymbol{P C M}}(\boldsymbol{l} / \boldsymbol{s})$ & 2017.50 & $\mathrm{~kg} / \mathrm{m}^{3}$ \\
\hline $\boldsymbol{A}_{\boldsymbol{P}}$ & 162.35 & $\mathrm{~cm}^{2}$ & $\boldsymbol{\rho}_{\boldsymbol{C}}$ (Aluminum) & 2700 & $\mathrm{~kg} / \mathrm{m}^{3}$ \\
\hline $\boldsymbol{W}_{\boldsymbol{F}}$ & 0.01 & $m m$ & $\boldsymbol{L}$ & 95.00 & $\mathrm{~kJ} / \mathrm{kg}$ \\
\hline $\boldsymbol{\Delta} \boldsymbol{T}$ & $6.20 ; 11.20 ; 16.20$ & $K$ & $\boldsymbol{K}_{\text {Flux }}$ & $15.56 ; 14.51 ; 13.59 ; 7.80 ; 7.29 ; 6.84$ & - \\
\hline
\end{tabular}

\subsection{Methodology of the experiments}

The experimental proof-of-concept has two main aims: The first one is the demonstration of the feasibility of the PCMflux concept. This aim is reached if the existence of a quasi-stationary phase change 
interface while moving the PCM can be demonstrated. The second aim is to experimentally validate the underlying theory given in section 3. Since the discharging of latent heat storage systems is the limiting factor, see section 1, the experiments focus on the discharging process.

At the beginning of each experiment, the HTF temperature is set to the discharging temperature. Three different discharging temperatures of $\Delta T=6.2 \mathrm{~K}, 11.2 \mathrm{~K}$ and $16.2 \mathrm{~K}$ between HTF temperature and melting temperature of the PCM are experimentally examined. After the HTF temperature has reached its constant set-value, the movement of the PCM containers is started.

The experiments end as soon as the PCM containers reach the end of the direction system on the other side of the heat exchanger. To secure same starting conditions for all experiments, the HTF temperature is then set to the corresponding temperature values $+\Delta \mathrm{T}$ above the melting temperature of the PCM. Afterwards, the containers are moved back to their original position. While their return, the PCM melts completely and a new discharging process starts.

In order to secure constant boundary conditions along the HTF flow through the heat exchanger pipe, a high volume flow of the HTF is realized. This leads to similar boundary conditions along the experimental setup. However, in this case the HTF does not significantly change temperature and the heat flux transferred into the HTF cannot be measured with sufficient accuracy. That is why the establishment of a quasi-stationary state is observed via thermography, rather than by measuring the heat flux. As soon as the position of the quasi-stationary phase change interface is locally-fixed, a constant heat flux is reached. During the experiments, the camera takes an image of the measuring area every $15 \mathrm{~s}$. The sequence of these images can then be used to evaluate the specific position of the phase change interface. The detection of the phase change interface makes use of a physical circumstance: While changing phase, the emission coefficient of the PCM changes. With the crystallizing PCM, the emission coefficient increases. After a complete phase change, the sensible cooling of the PCM is fast since no heat is released by further crystallization processes in these regions. This leads to comparably high detected signal differences between the solid and the liquid PCM on a small scale.

In addition to the three examined temperature differences, two different heights of the PCM inside the containers $H_{P C M}=5 \mathrm{~mm}$ and $10 \mathrm{~mm}$ are investigated experimentally, see Fig. 4 . In a first step, the maximum forward velocities $v_{\max }$ of each combination of examined parameters are predetermined via the underlying theory given in section 3. These are then validated by the experiments with the corresponding boundary conditions. Moving the PCM containers with $v_{\max }$, the position of the quasi- 
stationary phase change interface is expected to be established at the end of the active region of the heat exchanger, right before the containers are moved up by the ramp system, see Fig. 9 (a) and Fig. 11.

To check the results for consistency, not only the nominal forward velocities $v_{\max }$ are examined. Within additional experiments, the calculated $v_{\max }$ is reduced to $70 \% v_{\max }$ and raised to $130 \% v_{\max }$. All other conditions stay the same. In the case of $70 \% v_{\max }$, the location of the quasi-stationary phase change interface is expected to be located before the end of the active region of the heat exchanger. Contrarily, in the case of $130 \% v_{\max }$, the PCM should not have enough time to change phase. This is expected to result in an incomplete phase change. For the visualization of these different states see Fig. 9.

Tab. 3 shows the measurement matrix of the conducted experiments together with all important information. Each experiment with the corresponding forward velocity is numbered. The Roman numbers stand for different temperature differences $\Delta T$ for the different values for $H_{P C M}$. The Arabic numbering symbolizes the different forward velocities $100 \% v_{\max }, 70 \% v_{\max }$ and $130 \% v_{\max }$. These numbers are used for the assignment of the different experimental results to the involved parameters.

Tab. 3: Measuring matrix with the numbering system for each experiment together with all important parameters

\begin{tabular}{|c|c|c|c|c|c|c|c|c|}
\hline Parameter & Unit & No. & & Value & & \multicolumn{3}{|c|}{ Value } \\
\hline$H_{P C M}$ & $\mathrm{~mm}$ & & & 5 & & & 10 & \\
\hline$\Delta T$ & $K$ & & 6.20 & 11.20 & 16.20 & 6.20 & 11.20 & 16.20 \\
\hline$K_{\text {Flux }}$ & - & & 15.56 & 14.51 & 13.59 & 7.80 & 7.29 & 6.84 \\
\hline No. & & & $I$ & $I I$ & $I I I$ & $I V$ & $\bar{V}$ & $V I$ \\
\hline $100 \% v_{\max }$ & $\mathrm{mm} / \mathrm{s} \cdot 10^{-1}$ & $a$ & 1.70 & 3.00 & 4.24 & 0.43 & 0.75 & 1.07 \\
\hline $70 \% v_{\max }$ & $\mathrm{mm} / \mathrm{s} \cdot 10^{-1}$ & $\boldsymbol{b}$ & 1.19 & 2.10 & 2.97 & 0.30 & 0.53 & 0.75 \\
\hline $130 \% v_{\max }$ & $\mathrm{mm} / \mathrm{s} \cdot 10^{-1}$ & $c$ & 2.21 & 3.90 & 5.51 & 0.56 & 0.98 & 1.39 \\
\hline
\end{tabular}

\subsection{Results}

Fig. 13 - Fig. 15 show infrared images of the quasi-stationary states of all experiments conducted according to Tab. 3. The location of the corresponding measuring area is shown in Fig. 10 and Fig. 12. Fig. 13 gives the images for the experiments with $100 \% v_{\max }$, Fig. 14 for the experiments with $70 \% v_{\max }$ and Fig. 15 for $130 \% v_{\max }$. For the assignment of each experimental case see Tab. 3.

Within these figures, the PCM containers enter the heat exchanger from the right and exit on the left. The active region of the heat exchanger is marked by vertical dotted white lines on the right and on the 
left. As an example, see experiment la (Fig. 13 and Tab. 3): The containers entering the system from the right show a smooth colored surface. This signifies a completely molten salt. The periodic vertical interruptions along the heat exchanger are caused by the aluminum walls of the PCM containers, see Fig. 10. After passing the first vertical dotted white line and entering the active region of the heat exchanger, first structures within the PCM can be identified. In this state, the emissivity of the PCM starts to rise. This leads to an increase of the detected signal by the infrared camera and to a fictive increase in temperature. However, the PCM is still within phase change and the real temperature stays nearly constant. Further to the left, the PCM ends its transition process and solidifies. The resulting high temperature differences at this location represent the phase change interface. This position is emphasized by a thin red line and in example la close to the expected position at the end of the active region of the heat exchanger (vertical dotted white line on the left).

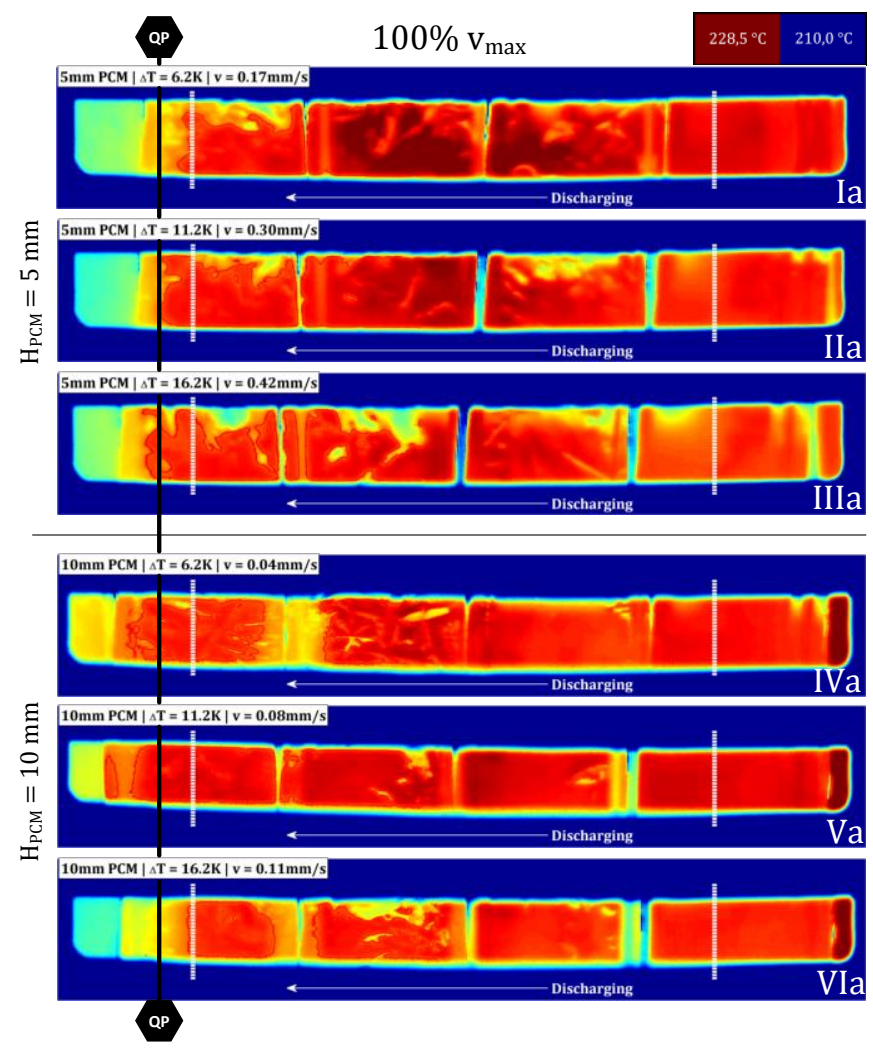

Fig. 13: Comparison of the positions of the quasi-stationary phase change interface for $100 \% v_{\max }$

In order to average the results for all experiments with the same relative forward velocities $100 \% v_{\max }$, $70 \% v_{\max }$ and $130 \% v_{\max }$, a black line for the averaged position of the quasi-stationary phase change interface (QP) is introduced. With this line, the position of the quasi-stationary phase change interface can be evaluated. For the case of $100 \% v_{\text {max }}$, see Fig. 13, this averaged position is close to the expected position at the end of the active region of the heat exchanger. This means that the predetermination of 
$100 \% v_{\max }$ depending on the different experimental circumstances is correct. Even though the boundary conditions vary significantly - the forward velocity changes by the maximum factor of 10.5 between IIla and IVa - the images of all experiments shown in Fig. 13 look similar. This proves the sufficient consideration of dimensionless circumstances.

In order to confirm these results, Fig. 14 shows the images of the quasi-stationary state of the experiments conducted with $70 \% v_{\max }$. The position of the quasi-stationary phase change interface is located before the end of the active region of the heat exchanger. This leads to a part load behavior of the storage system.

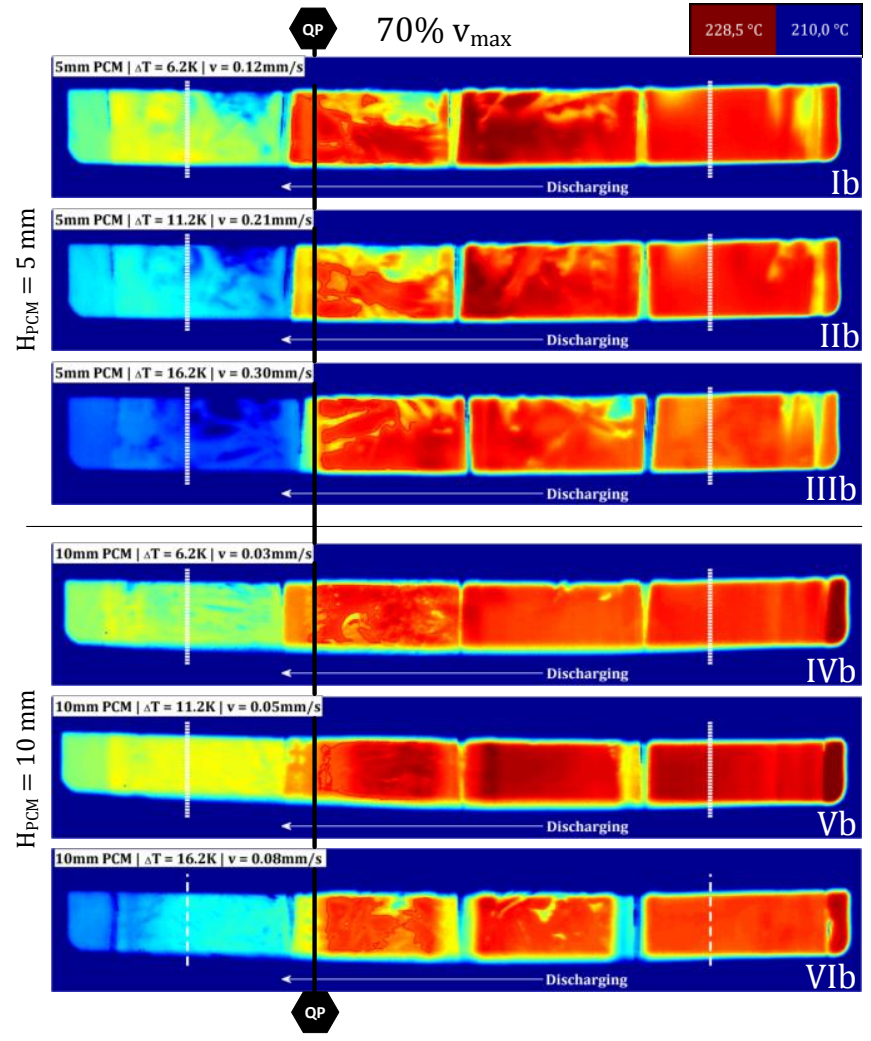

Fig. 14: Comparison of the positions of the quasi-stationary phase change interface for $70 \% v_{\max }$

Increasing the forward velocity to $130 \% v_{\max }$, the PCM containers are moved too quickly and the PCM does not completely change phase, see Fig. 15. After leaving the active region of the heat exchanger, the surface of the PCM appears to still be comparably smooth and does not show a significant temperature drop compared to the entrance of the PCM containers on the right.

All results show the expected behavior of the PCM inside the containers. Primarily, a quasi-stationary state is established and a successful operation of the PCMflux system is demonstrated experimentally. 
Secondly, the underlying theory of the PCMflux concept is validated successfully due to the position of the quasi-stationary phase change interface at the expected positions.

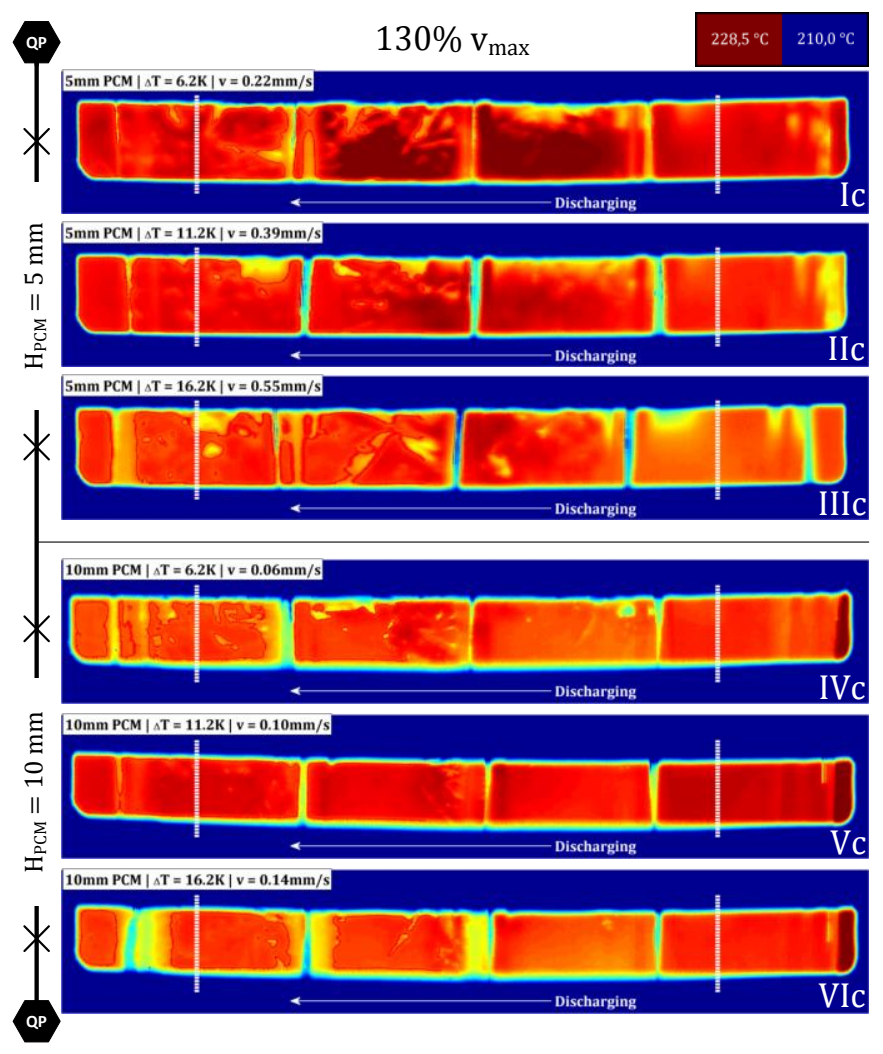

Fig. 15: Comparison of the positions of the quasi-stationary phase change interface for $130 \% v_{\max }$

\section{Conclusions}

Within this article, the PCMflux concept as an active latent heat storage system with separation of power and capacity was described and experimentally demonstrated. Most state-of-the-art latent heat storage systems show a significantly decreasing heat flux over time while discharging due to a growing and isolating layer of crystallized PCM sticking to the heat exchanger. The PCMflux concept overcomes this behavior by the mechanical separation of the storage material and the heat exchanger. For this purpose, the PCM is filled into containers. By moving them towards the heat exchanger, the crystallized PCM is transported from the heat exchanger and a growing layer of solidified PCM is avoided. To improve thermal contact between the components, a contacting fluid layer is introduced to the system. 
If the forward velocity of the PCM containers is chosen within a specific range, a quasi-stationary state with a complete phase change of the PCM is established and the phase change interface inside the PCM is locally-fixed, even though the containers are still moving. Therefore, a constant thermal power output is achieved. By adjusting the forward velocity, the level of the constant thermal power can be controlled. The relation between forward velocity and resulting heat flux thereby is described by a dimensionless number called $K_{\text {Flux }}$.

After providing the underlying theory of the PCMflux concept, an experimental setup as the proof-ofconcept of the PCMflux concept was described. The results of this setup proved the feasibility of the PCMflux concept by identifying the establishment of a quasi-stationary phase change interface at the predetermined positions. The agreement was demonstrated by a variation of temperature differences and different PCM layer thicknesses inside the PCM containers.

As a next step, the PCMflux concept is demonstrated in a scale of $10 \mathrm{~kW}$ within an enhanced experimental setup. Moreover, the main design parameters of the PCMflux concept will be optimized in order to reach high heat fluxes at lowest possible costs.

\section{References}

[1] D. Laing, C. Bahl, T. Bauer, D. Lehmann, and W.-D. Steinmann, "Thermal energy storage for direct steam generation," Sol. Energy, vol. 85, no. 4, pp. 627-633, Apr. 2011, DOI: 10.1016/j.solener.2010.08.015.

[2] J. F. Feldhoff, K. Schmitz, M. Eck, L. Schnatbaum-Laumann, D. Laing, F. Ortiz-Vives, and J. SchulteFischedick, "Comparative system analysis of direct steam generation and synthetic oil parabolic trough power plants with integrated thermal storage," Sol. Energy, vol. 86, no. 1, pp. 520-530, Jan. 2012, DOI: 10.1016/j.solener.2011.10.026.

[3] W.-D. Steinmann, D. Laing, and R. Tamme, "Latent Heat Storage Systems for Solar Thermal Power Plants and Process Heat Applications," J. Sol. Energy Eng., vol. 132, no. 2, p. 021003, 2010, DOI: 10.1115/1.4001405.

[4] H. Pointner, A. de Gracia, J. Vogel, N. H. S. Tay, M. Liu, M. Johnson, and L. F. Cabeza, "Computational efficiency in numerical modeling of high temperature latent heat storage: Comparison of selected software tools based on experimental data," Appl. Energy, vol. 161, pp. 337-348, 2016, DOI: 10.1016/j.apenergy.2015.10.020.

[5] D. Laing, T. Bauer, N. Breidenbach, B. Hachmann, and M. Johnson, "Development of high temperature phase-change-material storages," Appl. Energy, vol. 109, pp. 497-504, 2013, DOI: 10.1016/j.apenergy.2012.11.063. 
[6] T. Bauer, D. Laing, and R. Tamme, "Overview of PCMs for Concentrated Solar Power in the Temperature Range 200 to 350C," Adv. Sci. Technol., vol. 74, pp. 272-277, Oct. 2010, DOI: 10.4028/www.scientific.net/AST.74.272.

[7] H. L. Zhang, J. Baeyens, J. Degrève, G. Cáceres, R. Segal, and F. Pitié, "Latent heat storage with tubular-encapsulated phase change materials (PCMs)," Energy, vol. 76, 2014, DOI: 10.1016/j.energy.2014.03.067.

[8] B. Zalba, J. Marıin, L. F. Cabeza, and H. Mehling, "Review on thermal energy storage with phase change: materials, heat transfer analysis and applications," Appl. Therm. Eng., vol. 23, no. 3, pp. 251-283, Feb. 2003, DOI: 10.1016/S1359-4311(02)00192-8.

[9] H. Pointner, W.-D. Steinmann, and M. Eck, "Introduction of the PCM Flux Concept for Latent Heat Storage," Energy Procedia, vol. 57, pp. 643-652, 2014, DOI: 10.1016/j.egypro.2014.10.219.

[10] P. P. Levin, A. Shitzer, and G. Hetsroni, "Numerical optimization of a PCM-based heat sink with internal fins," Int. J. Heat Mass Transf., vol. 61, no. 1, pp. 638-645, 2013, DOI: 10.1016/j.ijheatmasstransfer.2013.01.056.

[11] T. Rozenfeld, Y. Kozak, R. Hayat, and G. Ziskind, “Close-contact melting in a horizontal cylindrical enclosure with longitudinal plate fins: Demonstration, modeling and application to thermal storage," Int. J. Heat Mass Transf., vol. 86, pp. 465-477, 2015, DOI: 10.1016/j.ijheatmasstransfer.2015.02.064.

[12] Z. Liu, X. Sun, and C. Ma, "Experimental investigations on the characteristics of melting processes of stearic acid in an annulus and its thermal conductivity enhancement by fins," Energy Convers. Manag., vol. 46, no. 6, pp. 959-969, 2005, DOI: 10.1016/j.enconman.2004.05.012.

[13] A. a. Al-Abidi, S. Mat, K. Sopian, M. Y. Sulaiman, and A. T. Mohammad, "Internal and external fin heat transfer enhancement technique for latent heat thermal energy storage in triplex tube heat exchangers," Appl. Therm. Eng., vol. 53, no. 1, pp. 147-156, 2013, DOI:

10.1016/j.applthermaleng.2013.01.011.

[14] N. H. S. Tay, F. Bruno, and M. Belusko, "Comparison of pinned and finned tubes in a phase change thermal energy storage system using CFD," Appl. Energy, vol. 104, pp. 79-86, 2013, DOI: 10.1016/j.apenergy.2012.10.040.

[15] J. N. W. Chiu and V. Martin, "Submerged finned heat exchanger latent heat storage design and its experimental verification," Appl. Energy, vol. 93, pp. 507-516, 2012, DOI: 10.1016/j.apenergy.2011.12.019.

[16] D. Zhao and G. Tan, "Numerical analysis of a shell-and-tube latent heat storage unit with fins for air-conditioning application," Appl. Energy, vol. 138, pp. 381-392, 2015, DOI:

10.1016/j.apenergy.2014.10.051.

[17] D. Singh, W. Zhao, W. Yu, D. M. France, and T. Kim, "Analysis of a graphite foam-NaCl latent heat storage system for supercritical CO2 power cycles for concentrated solar power," Sol. Energy, vol. 118, pp. 232-242, 2015, DOI: 10.1016/j.solener.2015.05.016.

[18] Z. Wang, Z. Zhang, L. Jia, and L. Yang, "Paraffin and paraffin/aluminum foam composite phase change material heat storage experimental study based on thermal management of Li-ion battery," Appl. Therm. Eng., vol. 78, pp. 428-436, 2015, DOI: 10.1016/j.applthermaleng.2015.01.009. 
[19] Z. Zhang, N. Zhang, J. Peng, X. Fang, X. Gao, and Y. Fang, "Preparation and thermal energy storage properties of paraffin/expanded graphite composite phase change material," Appl. Energy, vol. 91, no. 1, pp. 426-431, 2012, DOI: 10.1016/j.apenergy.2011.10.014.

[20] J. Darkwa and O. Su, "Thermal simulation of composite high conductivity laminated microencapsulated phase change material (MEPCM) board," Appl. Energy, vol. 95, pp. 246-252, 2012, DOI: 10.1016/j.apenergy.2012.02.062.

[21] H. Tian, W. Wang, J. Ding, X. Wei, M. Song, and J. Yang, "Thermal conductivities and characteristics of ternary eutectic chloride/expanded graphite thermal energy storage composites," Appl. Energy, vol. 148, pp. 87-92, 2015, DOI: 10.1016/j.apenergy.2015.03.020.

[22] M. Medrano, M. O. Yilmaz, M. Nogues, I. Martorell, J. Roca, and L. F. Cabeza, "Experimental evaluation of commercial heat exchangers for use as PCM thermal storage systems," Appl. Energy, vol. 86, no. 10, pp. 2047-2055, Oct. 2009, DOI: 10.1016/j.apenergy.2009.01.014.

[23] H. Shabgard, T. L. Bergman, N. Sharifi, and a. Faghri, "High temperature latent heat thermal energy storage using heat pipes," Int. J. Heat Mass Transf., vol. 53, no. 15-16, pp. 2979-2988, Jul. 2010, DOI: 10.1016/j.ijheatmasstransfer.2010.03.035.

[24] H. Shabgard, C. W. Robak, T. L. Bergman, and A. Faghri, "Heat transfer and exergy analysis of cascaded latent heat storage with gravity-assisted heat pipes for concentrating solar power applications," Sol. Energy, vol. 86, no. 3, pp. 816-830, Mar. 2012, DOI:

10.1016/j.solener.2011.12.008.

[25] K. Nithyanandam and R. Pitchumani, "Computational studies on a latent thermal energy storage system with integral heat pipes for concentrating solar power," Appl. Energy, vol. 103, pp. 400415, 2013, DOI: 10.1016/j.apenergy.2012.09.056.

[26] K. Nithyanandam and R. Pitchumani, "Design of a latent thermal energy storage system with embedded heat pipes," Appl. Energy, vol. 126, pp. 266-280, 2014, DOI: 10.1016/j.apenergy.2014.03.025.

[27] V. Zipf, A. Neuhäuser, D. Willert, P. Nitz, S. Gschwander, and W. Platzer, "High temperature latent heat storage with a screw heat exchanger: Design of prototype," Appl. Energy, vol. 109, pp. 462469, Dec. 2013, DOI: 10.1016/j.apenergy.2012.11.044.

[28] W.-D. Steinmann, "Speichersystem zur Speicherung thermischer Energie, Patent," DE 102004020 993 B4 2009.12.31, 2009.

[29] H. Pointner, W.-D. Steinmann, M. Eck, and C. Bachelier, "Separation of Power and Capacity In latent Heat Energy Storage," Energy Procedia, vol. 69, pp. 997-1005, 2015, DOI: 10.1016/j.egypro.2015.03.189.

[30] E. Buckingham, "On physically similar systems; Illustrations of the use of dimensional equations," Phys. Rev., vol. IV, no. 4, pp. 345-376, 1914.

[31] H. Pointner, W.-D. Steinmann, and M. Eck, "PCMflux as a fully controllable dynamic latent heat storage system," in Eurotherm Seminar N99 - Advances in Thermal Energy Storage, 2014.

[32] G. J. Janz and G. N. Truong, "Melting and Premelting Properties of the KNO3-NaNO2-NaNO3 Eutectic System," J. Chem. Eng. Data, vol. 28, pp. 201-202, 1983, DOI: 10.1021/je00032a022.

[33] J. W. Raade and D. Padowitz, "Development of Molten Salt Heat Transfer Fluid With Low Melting 
Point and High Thermal Stability," J. Sol. Energy Eng., vol. 133, no. 3, 2011, DOI: 10.1115/1.4004243. 